\title{
PENINGKATAN HASIL BELAJAR PADA MATERI TAJWID MATA PELAJARAN BTQ (BACA TULIS AL-QURAN) DENGAN METODE UMMI
}

\author{
MOCHAMMAD SHOFWAN HIDAYATULLOH
}

SD Negeri Kepuh Kiriman 1 Waru Kabupaten Sidoarjo

E-mail: shofwanhidayatulloh301993@gmail.com

\begin{abstract}
ABSTRAK
Penelitian ini bertujuan untuk meningkatkan hasil belajar siswa pada materi tajwid mata pelajaran Baca Tulis al-Quran (BTQ) dengan menggunakan Metode Ummi. Subjek penelitian ini adalah siswa kelas IV-A SD Negeri Kepuh Kiriman 1 Waru Kabupaten Sidoarjo. Penelitian ini merupakan penelitian tindakan kelas (Classroom Action Research) yang dilakukan secara kolaboratif dan partisipasi. Teknik pengumpulan data menggunakan metode observasi, tes dan dokumentasi. Data yang diperoleh dari hasil observasi dan tes selama proses belajar mengajar, selanjutnya dianalisis dengan menggunakan statistik deskriptif. Penelitian ini dikatakan berhasil jika hasil belajar peserta didik yang telah mencapai kriteria ketuntasan minimal (KKM) di atas $80 \%$. Hasil penelitian menunjukan bahwa penerapan metode Ummi pada materi tajwid dapat meningkatkan hasil belajar siswa. Hal ini dapat dilihat pada kenaikan prosentase siswa mendapat nilai di atas KKM tiap siklusnya. Pada tahapan pra siklus, dari jumlah 28 siswa yang mendapat nilai di atas KKM sebesar 29\% dengan nilai rata-rata kelas 61,43, pada tahapan siklus I siswa yang mendapat nilai di atas KKM sebebsar 43\% dengan nilai rata-rata kelas 72,86 dan pada tahapan siklus II siswa yang mendapat nilai di atas KKM sebesar 93\% dengan nilai ratarata kelas 91,43. Sehingga dari hasil penelitian ini dapat memberikan perubahan nilai yang signifikan.
\end{abstract}

Kata Kunci: Hasil Belajar, Tajwid, Baca Tulis Al-Quran, Metode Ummi

\section{ABSTRACT}

This study aims to improve student learning outcomes in recitation material in the Al-Quran Reading and Writing (BTQ) subject using the Ummi Method. The subjects of this study were students of class IV-A SD Negeri Kepuh Sendan 1 Waru, Sidoarjo Regency. This research is a classroom action research (Classroom Action Research) which is carried out in a collaborative and participatory manner. Data collection techniques using the method of observation, tests and documentation. The data obtained from the results of observations and tests during the teaching and learning process were then analyzed using descriptive statistics. This research is said to be successful if the learning outcomes of students who have reached the minimum completeness criteria (KKM) are above $80 \%$. The results showed that the application of the Ummi method on recitation material could improve student learning outcomes. This can be seen in the increase in the percentage of students who score above the KKM in each cycle. In the pre-cycle stage, of the total 28 students who scored above the KKM by $29 \%$ with an average grade of 61.43 , in the first cycle stage the students who scored above the KKM were $43 \%$ with an average grade of 72,86 and at the stage of the second cycle, students who scored above the KKM were 93\% with an average grade of 91.43 . So from the results of this study can provide a significant change in value.

Keywords: Learning Outcomes, Tajweed, Reading and Writing Al-Quran, Ummi . Method

\section{PENDAHULUAN}

Umat Islam mempunyai kitab suci sebagai pedoman hidup yang bernama al-Quran. AlQuran mempunyai nilai ibadah dan pahala yang sangat luar biasa bagi pembacanya, lebih-lebih mengamalkannya (Gunawan, 2013). Agar umat Islam mampu membaca al-Quran dengan fasih (lancar) dan benar sesuai dengan kaidah atau kaidahnya maka perlu diadakan suatu pembelajaran al-Quran. Karena apabila membaca al-Quran tidak disertai dengan kaidah atau aturan yang benar maka akan berakibat pada kesalahan dalam pemaknaan al-Quran. Kaidah 
yang harus diperhatikan yaitu, ilmu tajwid, makharijul huruf (tempat keluarnya huruf), dan gharib (Abdurohim, 2012). Tentu saat membaca al-Quran tidak boleh asal-asalan, harus sesuai dengan kaidah-kaidah ilmu al-Quran seperti ilmu tajwid, ilmu gharib, makharijul huruf beserta fasahahnya. Oleh karena itu mempelajari al-Quran ditanamkan sejak dini agar ketika dewasa nanti tidak kesulitan dalam membacanya. Salah satu isi pendidikan Islam adalah ilmu pengetahuan yang dimulai dengan keterampilan membaca dan menulis serta pengembangan ilmu yang lainnya (Muthoifin \& Nuha, 2018).

Sejalan dengan cara membaca al-Quran dengan memperhatikan kaidah ilmu tajwid, di SDN Kepuh Kiriman 1 Waru terdapat satu kasus yang harus segera dicarikan solusinya. Berdasarkan hasil observasi, peserta didik SDN Kepuh Kiriman 1 Waru memiliki pemahaman konsep dan hasil belajar yang rendah pada materi tajwid mata pelajaran BTQ. Khususnya peserta didik kelas IV-A. Hal ini dikarenakan metode yang disampaikan guru bersifat monoton karena hanya mengandalkan materi berbentuk teks dan penugasan. Dari hasil pengamatan nilai siswa sebelum tindakan, dapat diketahui bahwa secara keseluruhan, hasil belajar siswa kelas IV-A SDN Kepuh Kiriman 1 Waru sebelum dilakukan tindakan memperoleh rata-rata 61,43. Sedangkan KKM (Kriteria Ketuntasan Minimal) yang ditetapkan oleh guru pada kompetensi ini adalah 78. Hasil ini tentu tidak sesuai dengan harapan guru. Ketuntasan yang dicapai menunjukkan bahwa dari 28 siswa kelas IV-A, hanya 8 siswa atau 28\% yang dapat mencapai KKM dan 20 siswa lainnya atau $72 \%$ belum mencapai batas ketuntasan. Melihat situasi ini, maka diperlukan metode dan media yang dapat meningkatkan hasil belajar peserta didik agar esensi dari pembelajaran tetap dapat tersampaikan dengan baik. Hasil belajar adalah sebagai terjadinya perubahan tingkah laku pada diri peserta didik yang dapat diamati dan diukur bentuk pengetahuan, sikap dan keterampilan (Hamalik, 2007).

Seorang guru dituntut untuk menguasai berbagai kompetensi (kecakapan) dalam melaksanakan profesi keguruanya agar dapat menciptakan lingkungan belajar yang baik bagi peserta didik, sehingga tujuan pembelajaran dan pengajaran dapat tercapai dengan maksimal dan optimal. Salah satu kompetensi yang harus dimiliki oleh seorang guru yaitu profesional. Guru profesional yaitu orang yang memiliki kemampuan dan keahlian khusus dalam bidang keguruan sehingga ia mampu melakukan tupoksinya sebagai guru dengan kemampuan maksimal (Usman, 2010). Melihat persoalan ini, penulis sebagai seorang guru perlu bertindak untuk mewujudkan suatu inovasi metode pembelajaran yang simpel dan praktis untuk memudahkan guru sehingga mutu dan esensi pembelajaran yang diberikan dapat tersampaikan dengan baik. Salah satu metode pembelajaran yang bisa diterapkan adalah Metode Ummi.

Metode Ummi adalah salah satu metode membaca al-Quran dengan bacaan tartil. Metode Ummi menggunakan alat bantu sebuah buku yang disusun oleh Masruri dan Yusuf. Metode Ummi memiliki suatu yang beda dengan yang lainnya yaitu terletak pada sistem yang digunakan. Metode Ummi yang lahir sejak 2011 yang berarti termasuk metode yang baru di tengah-tengah masyarakat akan tetapi sampai saat ini telah digunakan oleh lebih dari 1000 lembaga di 24 provinsi di Indonesia (Erwiyanto, 2016).

Kata Ummi berasal dari bahasa arab yaitu "Ummun" yang bermakna ibuku dengan penambahan " $\mathrm{Ya}$ ' Mutakallim". Penggunaan istilah Ummi juga untuk menghormati dan mengingat jasa ibu yang telah berjasa pada kita semua. Ibulah yang mengajarkan banyak hal kepada kita dan orang yang sukses mengajarkan bahasa di dunia ini adalah ibu. Pendekatan yang digunakan dalam pembelajaran al-Quran metode Ummi adalah pendekatan bahasa ibu (Yusuf, 2016).

Strategi pendekatan bahasa ibu ada tiga: 1) Direct Method (Langsung) yaitu langsung dibaca tanpa dieja/diurai atau tidak banyak penjelasan. Atau dengan kata lain learning by doing, belajar dengan melakukan secara langsung. 2) Repetition (Diulang-Ulang) maksudnya adalah bacaan Al-Quran akan semakin kelihatan, keindahan, kekuatan, dan kemudahannya ketika kita mengulang-ulang ayat atau surat dalam Al-Quran. Begitu pula seorang ibu dalam mengajarkan bahasa kepada anaknya. 3) Affection (kasih sayang yang tulus) yaitu kekuatan cinta, kasih sayang yang tulus, dan kesabaran seorang ibu dalam mendidik anak adalah kunci 
kesuksesannya. Demikian juga seorang guru yang mengajar al-Quran jika ingin sukses hendaknya meneladani seorang ibu agar guru juga dapat menyentuh hati siswa mereka (Ummi Foundation, 2013).

Tahapan-tahapan pembelajaran metode Ummi merupakan langkah-langkah mengajar yang harus dilakukan seorang guru dalam proses belajar mengajar. Hal tersebut harus dijalankan secara berturut-turut sesuai dengan hierarkinya sebagaimana berikut ini: 1) Pembukaan, 2) Apersepsi, 3) Penanaman Konsep, 4) Pemahaman Konsep, 5) Latihan keterampilan, 6) Evaluasi, dan 7) Penutup (Kholidah, 2019).

Berdasarkan uraian tentang latar belakang di atas, penulis meneliti tentang Peningkatan Hasil Belajar Pada Materi Tajwid Mata Pelajaran BTQ (Baca Tulis Al-Quran) dengan Metode Ummi. Adapun rumusan masalah adalah bagaimana meningkatkan hasil belajar pada materi tajwid mata pelajaran BTQ dengan menggunakan metode Ummi. Sedangkan tujuan penelitian ini adalah 1) memperbaiki proses pembelajaran pada mata pelajaran BTQ dengan menggunakan metode Ummi. 2) dapat meningkatkan pengetahuan dan mengembangkan keterampilan dalam pemilihan metode pembelajaran yang menarik dan efektif sehingga dapat meningkatkan hasil belajar peserta didik dan 3) berusaha memberikan kontribusi positif untuk SD Negeri Kepuh Kiriman 1 Waru Kabupaten Sidoarjo.

\section{METODE PENELITIAN}

Metode penelitian yang digunakan adalah penelitian tindakan kelas (PTK) atau classroom action research yang berarti suatu kegiatan ilmiah yang dilakukan oleh guru dalam kelasnya dengan jalan menyusun rancangan, menjalankan, mengamati serta merefleksikan kegiatankegiatan yang telah dilakukan. Sedangkan teknik pengumpulan data menggunakan metode observasi, tes dan dokumentasi. Data yang diperoleh dari hasil observasi dan tes selama proses belajar mengajar, selanjutnya dianalisis dengan menggunakan statistik deskriptif. Penelitian ini dikatakan berhasil jika hasil belajar peserta didik yang telah mencapai kriteria ketuntasan minimal (KKM) di atas $80 \%$. Penelitian ini bertujuan untuk mengetahui peningkatan hasil belajar materi tajwid mata pelajaran BTQ menggunakan metode Ummi. Penelitian tindakan kelas ini dilakukan di SD Negeri Kepuh Kiriman 1 Waru Kabupaten Sidoarjo. Penelitian ini dilaksanakan di bulan Oktober 2021 semester ganjil tahun pelajaran 2021-2022. Subjek dalam penelitian ini adalah siswa kelas IV-A yang berjumlah 28 siswa terdiri dari 15 siswa laki-laki dan 13 siswa perempuan.

Penelitian ini dilakukan dengan siklus yang terdiri dari siklus I dan siklus II. Kedua siklus tersebut dilakukan dengan tahapan sebagai berikut: 1) Perencanaan, pada tahap ini akan dilakukan pembuatan RPP materi tajwid mata pelajaran BTQ dan menyiapkan segala alat dan media yang dibutuhkan. 2) Tindakan, pada tahap ini melaksanakan tindakan sesuai RPP yang telah direncanakan dengan beberapa tahapan metode Ummi yaitu pembukaan, apersepsi, penanaman konsep, pemahaman konsep, latihan keterampilan, evaluasi, dan penutup. 3) Pengamatan, pada tahap ini guru mengamati proses kegiatan yang sedang berlangsung dengan memperhatikan tahapan-tahapan pada metode Ummi. 4) Refleksi, pada tahap ini dilakukan untuk mengevaluasi seluruh tindakan yang telah dilakukan berdasarkan hasil pengamatan dan menyusun rencana perbaikan untuk digunakan pada siklus kedua. Pada penelitian ini, peneliti bertindak sebagai perancang dan pelaksana kegiatan. Berikut alur penelitian tindakan kelas : 


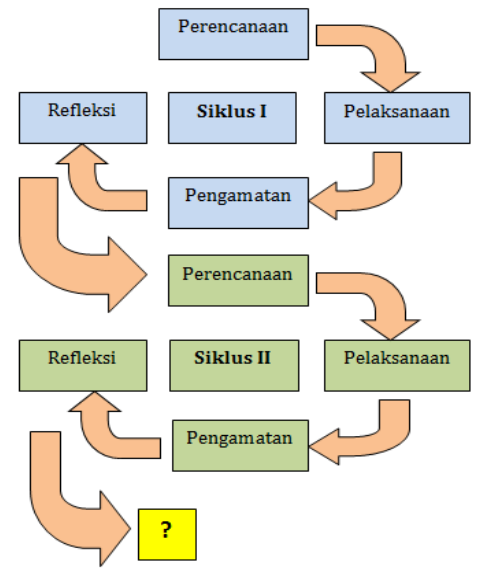

Gambar 1: Alur Penelitian Tindakan Kelas (PTK)

\section{HASIL DAN PEMBAHASAN}

\section{Hasil}

\section{Pra Siklus}

Hasil pengamatan tersebut dapat dideskripsikan sebagai berikut:

a. Guru memulai pembelajaran dengan mengucapkan salam dan tanya kabar kepada peserta didik. Pada saat pembelajaran dimulai, ditemukan beberapa peserta didik yang belum siap menerima materi dari guru. Melihat situasi seperti ini guru mengintruksikan semua peserta didik agar siap dan berkonsentrasi.

b. Metode yang digunakan guru adalah ceramah dan penugasan secara langsung. Guru menjelaskan materi dengan kondisi lebih banyak komunikasi sepihak (guru menjelaskan dan siswa mendengarkan) dan hanya mengandalkan buku paket dan LKS.

c. Waktu pembelajaran lebih banyak dipergunakan untuk mengerjakan soal-soal latihan LKS dengan bimbingan yang sangat minim, siswa diminta mengerjakan soal di LKS sementara guru hanya duduk santai di depan kelas. Sesekali ada siswa yang bertanya tentang soal yang belum mereka pahami, barulah guru mendekati dan memberikan penjelasan, begitu seterusnya sehingga tidak terasa waktu pembelajaran telah berakhir.

d. Di tengah proses pembelajaran masih terdapat siswa tidak memperhatiakan guru, masih ada yang ngobrol dan diam saja. Proses pembelajaran tidak berjalan aktif disebabkan siswa tidak berperan aktif secara langsung. Hal ini yang menyebabkan kurang interaktifnya guru dan siswa dalam menjadikan kelas yang aktif.

e. Hasil belajar yang masih rendah. Hal ini terlihat dari nilai siswa yang belum mencapai nilai KKM 78 pada pembelajaran BTQ tentang materi tajwid.

f. Masih banyak peserta didik yang belum mengerti dengan materi tersebut karena malu bertanya, terlalu sulit dan tidak percaya diri yang mengakibatkan peserta didik tidak semangat untuk belajar dan mencobanya.

Tabel 1 : Rekapitulasi Nilai Siswa Kelas IV-A Pra Siklus

\begin{tabular}{|c|l|c|c|c|}
\hline NO & \multicolumn{1}{|c|}{ NAMA } & L/P & NILAI & KETUNTASAN \\
\hline 1 & $\begin{array}{l}\text { AALEESYA DANIA KHUMAIRA P. } \\
\text { J. K. }\end{array}$ & P & 50 & $\begin{array}{c}\text { BELUM } \\
\text { TUNTAS }\end{array}$ \\
\hline 2 & ACHMAD RIFKY MUSTOFA & L & 40 & $\begin{array}{c}\text { BELUM } \\
\text { TUNTAS }\end{array}$ \\
\hline 3 & AHMAD REZA PUTRA KRISTA & L & 50 & $\begin{array}{c}\text { BELUM } \\
\text { TUNTAS }\end{array}$ \\
\hline 4 & ANNISA THUFAILLAH NAJWA & P & 30 & $\begin{array}{c}\text { BELUM } \\
\text { TUNTAS }\end{array}$ \\
\hline 5 & ARWINSYAH SLANIRO & L & 50 & $\begin{array}{c}\text { BELUM } \\
\text { TUNTAS }\end{array}$ \\
\hline
\end{tabular}




\begin{tabular}{|c|c|c|c|c|}
\hline NO & NAMA & $\mathbf{L} / \mathbf{P}$ & NILAI & KETUNTASAN \\
\hline 6 & BILQIS AZZAHRA & $\mathrm{P}$ & 50 & $\begin{array}{l}\text { BELUM } \\
\text { TUNTAS }\end{array}$ \\
\hline 7 & $\begin{array}{l}\text { DAYSAQ GHAZIY ALTHAF } \\
\text { BAAFSYAH }\end{array}$ & $\mathrm{L}$ & 30 & $\begin{array}{l}\text { BELUM } \\
\text { TUNTAS }\end{array}$ \\
\hline 8 & $\begin{array}{l}\text { ENZO RIZQULLAH } \\
\text { YULIWANTOKO }\end{array}$ & $\mathrm{L}$ & 50 & $\begin{array}{l}\text { BELUM } \\
\text { TUNTAS }\end{array}$ \\
\hline 9 & JIHAN ELYA AZIZAH & $\mathrm{P}$ & 40 & $\begin{array}{l}\text { BELUM } \\
\text { TUNTAS }\end{array}$ \\
\hline 10 & KEYSHA DEVITA PUTRI & $\mathrm{P}$ & 50 & $\begin{array}{l}\text { BELUM } \\
\text { TUNTAS }\end{array}$ \\
\hline 11 & KHOIRUN NISA' AISYAPUTRI & $\mathrm{P}$ & 70 & $\begin{array}{l}\text { BELUM } \\
\text { TUNTAS }\end{array}$ \\
\hline 12 & MUH. AHNAF ASYRAF FALAH & $\mathrm{L}$ & 50 & $\begin{array}{l}\text { BELUM } \\
\text { TUNTAS }\end{array}$ \\
\hline 13 & MUHAMAD DAFA AL FACHRI & $\mathrm{L}$ & 60 & $\begin{array}{c}\text { BELUM } \\
\text { TUNTAS } \\
\end{array}$ \\
\hline 14 & $\begin{array}{l}\text { MUHAMMAD ALTHAF ARIVO } \\
\text { SANTOSO }\end{array}$ & $\mathrm{L}$ & 60 & $\begin{array}{c}\text { BELUM } \\
\text { TUNTAS }\end{array}$ \\
\hline 15 & $\begin{array}{l}\text { MUHAMMAD KUKUH } \\
\text { VERDIANSYAH }\end{array}$ & $\mathrm{L}$ & 40 & $\begin{array}{l}\text { BELUM } \\
\text { TUNTAS }\end{array}$ \\
\hline 16 & $\begin{array}{l}\text { MUHAMMAD LUQMAN } \\
\text { ALFADILLAH }\end{array}$ & $\mathrm{L}$ & 60 & $\begin{array}{l}\text { BELUM } \\
\text { TUNTAS }\end{array}$ \\
\hline 17 & NAJIA AQILLA ROLINTAN & $\mathrm{P}$ & 60 & $\begin{array}{l}\text { BELUM } \\
\text { TUNTAS }\end{array}$ \\
\hline 18 & NAYLA BRILLIAN PRAMESWARI & $\mathrm{P}$ & 80 & TUNTAS \\
\hline 19 & NURSINTA MARISKA AURA & $\mathrm{P}$ & 90 & TUNTAS \\
\hline 20 & PUTRI CAHYANI & $\mathrm{P}$ & 60 & $\begin{array}{c}\text { BELUM } \\
\text { TUNTAS }\end{array}$ \\
\hline 21 & RAEESA NUR ARIN & $\mathrm{P}$ & 70 & $\begin{array}{l}\text { BELUM } \\
\text { TUNTAS }\end{array}$ \\
\hline 22 & RAFISQY IQBAL FAHREZA & $\mathrm{L}$ & 90 & TUNTAS \\
\hline 23 & RAKA YUANFALAH PRATAMA & $\mathrm{L}$ & 60 & $\begin{array}{c}\text { BELUM } \\
\text { TUNTAS }\end{array}$ \\
\hline 24 & RIZQI MAULANA MUSYAFFA & $\mathrm{L}$ & 90 & TUNTAS \\
\hline 25 & SAFA NABILA AULIA PUTRI & $\mathrm{P}$ & 90 & TUNTAS \\
\hline 26 & ZAHIRA PUTRI GREDNANDA & $\mathrm{P}$ & 80 & TUNTAS \\
\hline 27 & DEVAN ZEPTHANO & $\mathrm{L}$ & 90 & TUNTAS \\
\hline 28 & DIRGA ADITYA ADLI & $\mathrm{L}$ & 80 & TUNTAS \\
\hline \multicolumn{5}{|c|}{ TOTAL $: 1720$} \\
\hline \multicolumn{5}{|c|}{ RATA-RATA KELAS } \\
\hline \multicolumn{3}{|c|}{ NILAI TERTINGGI } & \multicolumn{2}{|l|}{$: 90$} \\
\hline \multicolumn{3}{|c|}{ NILAI TERENDAH } & \multicolumn{2}{|l|}{$: 30$} \\
\hline \multicolumn{3}{|c|}{$\begin{array}{r}\text { JUMLAH SISWA MENDAPAT NILAI DI ATAS } \\
\text { KKM } \\
\end{array}$} & \multicolumn{2}{|l|}{$: 8 / 29 \%$} \\
\hline \multicolumn{3}{|c|}{$\begin{array}{r}\text { JUMLAH SISWA MENDAPAT NILAI DI BAWAH } \\
\text { KKM }\end{array}$} & \multicolumn{2}{|c|}{$: 20 / 71 \%$} \\
\hline
\end{tabular}

\section{Siklus I}

Berdasarkan data siklus I diperoleh keterangan bahwa dari 28 siswa ada 12 siswa atau $43 \%$ yang mendapat nilai di atas Kriteria Ketuntasan Minimal (KKM) yaitu 78 dan dapat dikatakan bahwa siswa tersebut sudah mencapai ketuntasan belajar, sedangkan siswa yang mendapat nilai di bawah KKM ada 14 siswa atau $57 \%$ dan ini berarti siswa tersebut dikatakan belum tuntas belajar. Nilai rata-rata siswa pada siklus I adalah 72,86. Melihat 
data siklus I di atas maka diperlukan perbaikan atau refleksi untuk mempersiapkan siklus II. Hal ini dikarenakan siswa yang mencapai nilai di atas KKM masih di bawah $80 \%$.

Tabel 2 : Rekapitulasi Nilai Siswa Kelas IV-A Siklus I

\begin{tabular}{|c|c|c|c|c|}
\hline NO & NAMA & $\mathbf{L} / \mathbf{P}$ & NILAI & KETUNTASAN \\
\hline 1 & $\begin{array}{l}\text { AALEESYA DANIA KHUMAIRA P. } \\
\text { J. K. }\end{array}$ & $\mathrm{P}$ & 60 & $\begin{array}{l}\text { BELUM } \\
\text { TUNTAS }\end{array}$ \\
\hline 2 & ACHMAD RIFKY MUSTOFA & $\mathrm{L}$ & 60 & $\begin{array}{c}\text { BELUM } \\
\text { TUNTAS }\end{array}$ \\
\hline 3 & AHMAD REZA PUTRA KRISTA & $\mathrm{L}$ & 50 & $\begin{array}{l}\text { BELUM } \\
\text { TUNTAS }\end{array}$ \\
\hline 4 & ANNISA THUFAILLAH NAJWA & $\mathrm{P}$ & 90 & TUNTAS \\
\hline 5 & ARWINSYAH SLANIRO & $\mathrm{L}$ & 60 & $\begin{array}{c}\text { BELUM } \\
\text { TUNTAS }\end{array}$ \\
\hline 6 & BILQIS AZZAHRA & $\mathrm{P}$ & 50 & $\begin{array}{c}\text { BELUM } \\
\text { TUNTAS }\end{array}$ \\
\hline 7 & $\begin{array}{l}\text { DAYSAQ GHAZIY ALTHAF } \\
\text { BAAFSYAH }\end{array}$ & $\mathrm{L}$ & 60 & $\begin{array}{c}\text { BELUM } \\
\text { TUNTAS }\end{array}$ \\
\hline 8 & $\begin{array}{l}\text { ENZO RIZQULLAH } \\
\text { YULIWANTOKO } \\
\end{array}$ & $\mathrm{L}$ & 70 & $\begin{array}{c}\text { BELUM } \\
\text { TUNTAS } \\
\end{array}$ \\
\hline 9 & JIHAN ELYA AZIZAH & $\mathrm{P}$ & 60 & $\begin{array}{c}\text { BELUM } \\
\text { TUNTAS }\end{array}$ \\
\hline 10 & KEYSHA DEVITA PUTRI & $\mathrm{P}$ & 50 & $\begin{array}{c}\text { BELUM } \\
\text { TUNTAS }\end{array}$ \\
\hline 11 & KHOIRUN NISA' AISYAPUTRI & $\mathrm{P}$ & 80 & TUNTAS \\
\hline 12 & MUH. AHNAF ASYRAF FALAH & $\mathrm{L}$ & 70 & $\begin{array}{l}\text { BELUM } \\
\text { TUNTAS }\end{array}$ \\
\hline 13 & MUHAMAD DAFA AL FACHRI & $\mathrm{L}$ & 80 & TUNTAS \\
\hline 14 & $\begin{array}{l}\text { MUHAMMAD ALTHAF ARIVO } \\
\text { SANTOSO }\end{array}$ & $\mathrm{L}$ & 80 & TUNTAS \\
\hline 15 & $\begin{array}{l}\text { MUHAMMAD KUKUH } \\
\text { VERDIANSYAH }\end{array}$ & $\mathrm{L}$ & 60 & $\begin{array}{c}\text { BELUM } \\
\text { TUNTAS }\end{array}$ \\
\hline 16 & $\begin{array}{l}\text { MUHAMMAD LUQMAN } \\
\text { ALFADILLAH }\end{array}$ & $\mathrm{L}$ & 70 & $\begin{array}{c}\text { BELUM } \\
\text { TUNTAS } \\
\end{array}$ \\
\hline 17 & NAJIA AQILLA ROLINTAN & $\mathrm{P}$ & 60 & $\begin{array}{c}\text { BELUM } \\
\text { TUNTAS }\end{array}$ \\
\hline 18 & NAYLA BRILLIAN PRAMESWARI & $\mathrm{P}$ & 80 & TUNTAS \\
\hline 19 & NURSINTA MARISKA AURA & $\mathrm{P}$ & 90 & TUNTAS \\
\hline 20 & PUTRI CAHYANI & $\mathrm{P}$ & 60 & $\begin{array}{c}\text { BELUM } \\
\text { TUNTAS }\end{array}$ \\
\hline 21 & RAEESA NUR ARIN & $\mathrm{P}$ & 70 & $\begin{array}{l}\text { BELUM } \\
\text { TUNTAS }\end{array}$ \\
\hline 22 & RAFISQY IQBAL FAHREZA & $\mathrm{L}$ & 90 & TUNTAS \\
\hline 23 & RAKA YUANFALAH PRATAMA & $\mathrm{L}$ & 60 & $\begin{array}{l}\text { BELUM } \\
\text { TUNTAS }\end{array}$ \\
\hline 24 & RIZQI MAULANA MUSYAFFA & $\mathrm{L}$ & 100 & TUNTAS \\
\hline 25 & SAFA NABILA AULIA PUTRI & $\mathrm{P}$ & 100 & TUNTAS \\
\hline 26 & ZAHIRA PUTRI GREDNANDA & $\mathrm{P}$ & 90 & TUNTAS \\
\hline 27 & DEVAN ZEPTHANO & $\mathrm{L}$ & 100 & TUNTAS \\
\hline 28 & DIRGA ADITYA ADLI & $\mathrm{L}$ & 90 & TUNTAS \\
\hline \multicolumn{5}{|c|}{ TOTAL } \\
\hline \multicolumn{3}{|c|}{ RATA-RATA KELAS } & \multicolumn{2}{|l|}{$: 72,86$} \\
\hline \multicolumn{3}{|c|}{ NILAI TERTINGGI } & \multicolumn{2}{|l|}{$: 100$} \\
\hline \multicolumn{3}{|c|}{ NILAI TERENDAH } & \multicolumn{2}{|l|}{$: 50$} \\
\hline
\end{tabular}




\begin{tabular}{|c|c|c|c|}
\hline NO & NAMA & NILAI & KETUNTASAN \\
\hline & JUMLAH SISWA MENDAPAT NILAI DI ATAS & $: 12 / 439$ & \\
\hline & $\begin{array}{r}\text { MLAH SISWA MENDAPAT NILAI DI BAWAH } \\
\text { KKM }\end{array}$ & $: 16 / 570$ & \\
\hline
\end{tabular}

\section{Siklus II}

Berdasarkan data siklus II diperoleh keterangan bahwa dari 28 siswa ada 26 siswa atau $93 \%$ yang mendapat nilai di atas Kriteria Ketuntasan Minimal (KKM) yaitu 78 dan dapat dikatakan bahwa siswa tersebut sudah mencapai ketuntasan belajar, sedangkan siswa yang mendapat nilai di bawah KKM ada 2 siswa atau 7\% dan ini berarti siswa tersebut dikatakan belum tuntas belajar. Nilai rata-rata siswa pada siklus II adalah 91,43. Melihat data siklus II di atas maka bisa dikatakan penelitian ini berhasil atau tuntas dikarenakan siswa yang nilainya mencapai KKM lebih dari $80 \%$.

Tabel 3 : Rekapitulasi Nilai Siswa Kelas IV-A Siklus II

\begin{tabular}{|c|c|c|c|c|}
\hline NO & NAMA & $\mathbf{L} / \mathbf{P}$ & NILAI & KETUNTASAN \\
\hline 1 & $\begin{array}{l}\text { AALEESYA DANIA KHUMAIRA P. } \\
\text { J. K. }\end{array}$ & $\mathrm{P}$ & 80 & TUNTAS \\
\hline 2 & ACHMAD RIFKY MUSTOFA & $\mathrm{L}$ & 90 & TUNTAS \\
\hline 3 & AHMAD REZA PUTRA KRISTA & $\mathrm{L}$ & 90 & TUNTAS \\
\hline 4 & ANNISA THUFAILLAH NAJWA & $\mathrm{P}$ & 70 & BELUM TUNTAS \\
\hline 5 & ARWINSYAH SLANIRO & $\mathrm{L}$ & 100 & TUNTAS \\
\hline 6 & BILQIS AZZAHRA & $\mathrm{P}$ & 100 & TUNTAS \\
\hline 7 & $\begin{array}{l}\text { DAYSAQ GHAZIY ALTHAF } \\
\text { BAAFSYAH }\end{array}$ & $\mathrm{L}$ & 70 & BELUM TUNTAS \\
\hline 8 & $\begin{array}{l}\text { ENZO RIZQULLAH } \\
\text { YULIWANTOKO }\end{array}$ & $\mathrm{L}$ & 90 & TUNTAS \\
\hline 9 & JIHAN ELYA AZIZAH & $\mathrm{P}$ & 80 & TUNTAS \\
\hline 10 & KEYSHA DEVITA PUTRI & $\mathrm{P}$ & 90 & TUNTAS \\
\hline 11 & KHOIRUN NISA' AISYAPUTRI & $\mathrm{P}$ & 90 & TUNTAS \\
\hline 12 & MUH. AHNAF ASYRAF FALAH & $\mathrm{L}$ & 80 & TUNTAS \\
\hline 13 & MUHAMAD DAFA AL FACHRI & $\mathrm{L}$ & 100 & TUNTAS \\
\hline 14 & $\begin{array}{l}\text { MUHAMMAD ALTHAF ARIVO } \\
\text { SANTOSO }\end{array}$ & $\mathrm{L}$ & 80 & TUNTAS \\
\hline 15 & $\begin{array}{l}\text { MUHAMMAD KUKUH } \\
\text { VERDIANSYAH }\end{array}$ & $\mathrm{L}$ & 100 & TUNTAS \\
\hline 16 & $\begin{array}{l}\text { MUHAMMAD LUQMAN } \\
\text { ALFADILLAH }\end{array}$ & $\mathrm{L}$ & 100 & TUNTAS \\
\hline 17 & NAJIA AQILLA ROLINTAN & $\mathrm{P}$ & 100 & TUNTAS \\
\hline 18 & NAYLA BRILLIAN PRAMESWARI & $\mathrm{P}$ & 100 & TUNTAS \\
\hline 19 & NURSINTA MARISKA AURA & $\mathrm{P}$ & 100 & TUNTAS \\
\hline 20 & PUTRI CAHYANI & $\mathrm{P}$ & 90 & TUNTAS \\
\hline 21 & RAEESA NUR ARIN & $\mathrm{P}$ & 90 & TUNTAS \\
\hline 22 & RAFISQY IQBAL FAHREZA & $\mathrm{L}$ & 90 & TUNTAS \\
\hline 23 & RAKA YUANFALAH PRATAMA & $\mathrm{L}$ & 100 & TUNTAS \\
\hline 24 & RIZQI MAULANA MUSYAFFA & $\mathrm{L}$ & 100 & TUNTAS \\
\hline 25 & SAFA NABILA AULIA PUTRI & $\mathrm{P}$ & 100 & TUNTAS \\
\hline 26 & ZAHIRA PUTRI GREDNANDA & $\mathrm{P}$ & 90 & TUNTAS \\
\hline 27 & DEVAN ZEPTHANO & $\mathrm{L}$ & 90 & TUNTAS \\
\hline 28 & DIRGA ADITYA ADLI & $\mathrm{L}$ & 100 & TUNTAS \\
\hline \multicolumn{5}{|c|}{ TOTAL } \\
\hline \multicolumn{3}{|c|}{ RATA-RATA KELAS } & \multicolumn{2}{|l|}{$: 91,43$} \\
\hline \multicolumn{3}{|c|}{ NILAI TERTINGGI } & \multicolumn{2}{|l|}{$: 100$} \\
\hline \multicolumn{3}{|c|}{ NILAI TERENDAH } & \multicolumn{2}{|l|}{$: 70$} \\
\hline
\end{tabular}




\begin{tabular}{|c|c|c|c|}
\hline NO & NAMA & NILAI & KETUNTASAN \\
\hline & \multicolumn{3}{|c|}{$\begin{array}{r}\text { JUMLAH SISWA MENDAPAT NILAI DI ATAS }: 26 / 93 \% \\
\text { KKM }\end{array}$} \\
\hline & $\begin{array}{r}\text { JMLAH SISWA MENDAPAT NILAI DI BAWAH } \\
\text { KKM }\end{array}$ & $2 / 7 \%$ & \\
\hline
\end{tabular}

Dari mulai pra siklus - siklus II telah mengalami perubahan yang signifikan dengan dibuktikan meningkatnya nilai hasil belajar siswa kelas IV-A pada materi tajwid mata pelajaran BTQ dengan menggunakan metode Ummi. Prosedur dari keberhasilan ini adalah dengan tercapainya nilai di atas angka $78(\mathrm{KKM})$ dengan prosentase $80 \%$ dari jumlah siswa. Berikut gambar grafik yang menunjukkan progres hasil belajar siswa kelas IV-A dari pra siklus - siklus II :

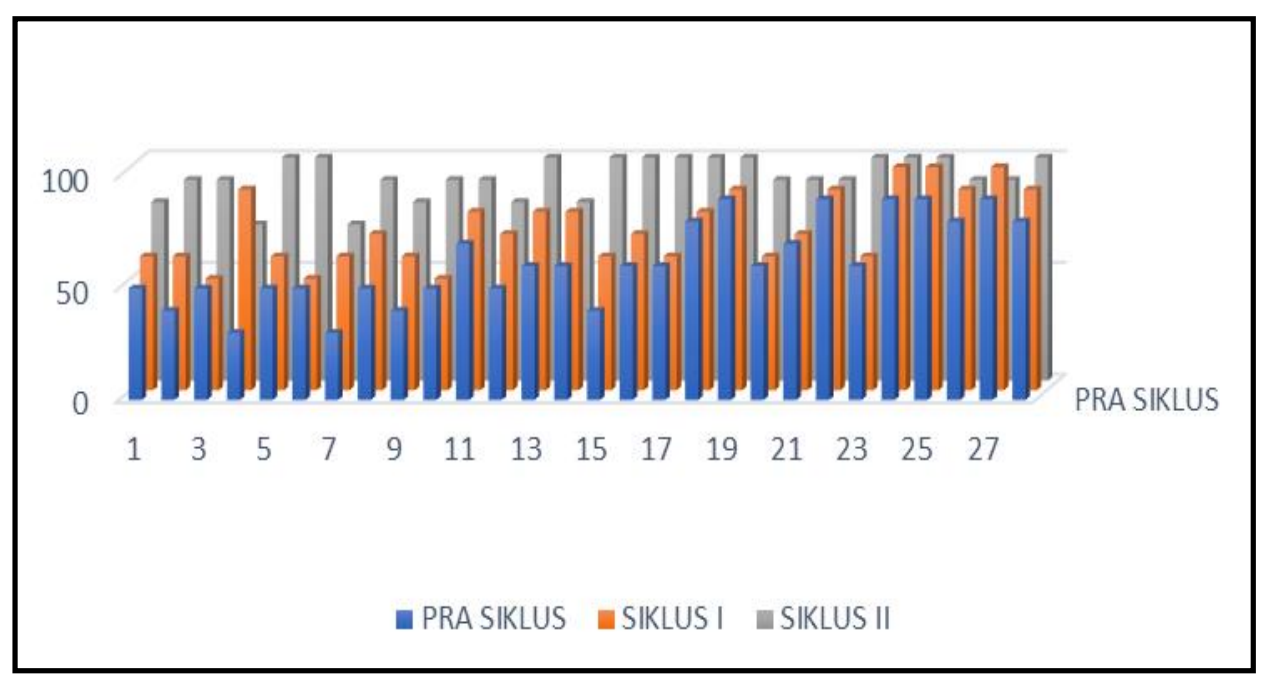

Gambar 1 : Grafik Nilai Hasil Belajar Siswa Kelas IV-A Pra Siklus - Siklus II

\section{Pembahasan}

Pelaksanaan pembelajaran pada siklus I peneliti mengadakan penelitian sesuai dengan Rencana Pelaksanaan Pembelajaran (RPP), dimana hasil yang diperoleh peserta didik masih banyak yang di bawah ketuntasan sekitar 57\% dan 43\% siswa yang di atas KKM. Namun hasil belajar pada siklus I mengalami kemajuan dari pada Pra Siklus Peneliti sudah melaksanakan pembelajaran sesuai dengan RPP sekaligus menerapkan metode Ummi kepada siswa. Memang metode yang diterapkan pada saat itu masih terbilang baru dan siswa belum terbiasa dengan metode tersebut mengingat metode Ummi adalah metode yang penyampaiannya secara cepat dan membutuhkan daya ingat yang kuat.

Pada pembelajaran siklus II menunjukkan bahwa proses pembelajaran menggunakan metode Ummi yang dilakukan oleh guru sudah menunjukan hasil yang positif seperti yang diharapkan peneliti dalam pelaksanaannya. Hal ini terbukti dengan hasil belajar siswa yang di atas KKM mencapai 93\%. Artinya penelitian ini dikatakan berhasil dan tuntas yang telah melebihi dari $80 \%$ pencapaian hasil belajar siswa di atas KKM.

Penerapan metode Ummi pada siswa kelas IV-A sangat berpengaruh pada hasil belajar kognitif yang telah dicapai. Hasil tes menunjukkan bahwa rata-rata kelas sebelum menerapkan metode Ummi adalah 61,43 menjadi 72,86 pada siklus I dan meningkat menjadi 91,43 pada siklus II. Dengan demikian penerapan metode Ummi dalam penelitian ini menunjukkan perubahan positif pada hasil belajar siswa.

Hasil penelitian ini selaras dengan penelitian dari Delfi Fajriani (2019) yang berjudul Implementasi Metode Ummi Untuk Meningkatkan Kemampuan Bacaan Al-Quran Siswa di SMP-IT Anni'mah Margahayu. Hasil dari penelitian ini adalah (1) Metode Ummi mempunyai tahapan-tahapan dalam pembelajarannya yaitu: pembukaan, apersepsi, penanaman konsep, pemahaman konsep, keterampilan/latihan, evaluasi dan penutup. (2) Berdasarkan hasil analisis Uji Paired Sampel T-test pada kelas eksperimen yang mendapat perlakuan belajar 
menggunakan metode Ummi, diketahui bahwa nilai sig. (2-tailed) sebesar 0,000<0,05. Karena nilai sig. (2-tailed) 0,000 lebih kecil dari 0,05 maka dapat disimpulkan bahwa penggunaan metode Ummi pada kelas eksperimen dapat meningkatkan kemampuan bacaan al-Quran siswa.

\section{KESIMPULAN}

Pembelajaran materi tajwid mata pelajaran BTQ dengan menggunakan metode Ummi dengan menerapkan tahapan pembukaan, apersepsi, penanaman konsep, pemahaman konsep, keterampilan/latihan, evaluasi dan penutup dapat meningkatkan hasil belajar siswa. Hal ini tentu sangat membantu siswa yang merasa kesulitan dalam menerima materi tajwid sehingga pengetahuan dan keterampilan dapat dikuasai dengan penanaman konsep, pemahaman konsep dan keterampilan dari metode Ummi.

Hasil belajar siswa pada materi tajwid dengan menggunakan metode Ummi berada pada kategori baik dan berhasil. Hal ini dapat dilihat pada kenaikan prosentase siswa mendapat nilai di atas KKM tiap siklusnya. Pada tahapan pra siklus siswa yang mendapat nilai di atas KKM sebesar 29\% dengan nilai rata-rata kelas 61,43, pada tahapan siklus I siswa yang mendapat nilai di atas KKM sebebsar 43\% dengan nilai rata-rata kelas 72,86 dan pada tahapan siklus II siswa yang mendapat nilai di atas KKM sebesar 93\% dengan nilai rata-rata kelas 91,43. Melihat data tersebut tentu metode Ummi dinilai berhasil untuk meningkatkan hasil belajar pada materi tajwid yang sebelumnya hanya menggunakan metode klasik.

\section{DAFTAR PUSTAKA}

A. Yusuf MS. (2016). Penggunaan Media Visual Dalam Pembelajaran Al-Qur'an Metode Ummi (Studi Kasus di SD Al Falah Assalam Sidoarjo). Tesis. Universitas Islam Negeri Sunan Ampel. Surabaya.

Abdurohim, Acep Lim. (2012). Ilmu Tajwid Lengkap. Bandung: CV Penerbit Diponegoro.

Erwiyanto. (2016). Al-Itqan Panduan Komprehensif Memahami Bacaan Graraib dan Musykilat Al-Qur'an Menurut Imam 'Ashim Riwayat Hafsh Thariq Al-Syatibiyyah. Surabaya: Lembaga Ummi Foundation.

Fajriani, Delfi. (2019). Implementasi Metode Ummi Untuk Meningkatkan Kemampuan Bacaan Al-Quran Siswa di SMPIT Anni'mah Margahayu. Diakses 03 Februari 2022 dari https://ojs.pps-ibrahimy.ac.id/index.php/jpii/article/view/137/94

Foundation, Ummi. (2013). Modul Sertifikat Guru Metode Ummi. Surabaya: Ummi Foundation.

Gunawan, Heri. (2013). Kurikulum dan Pembelajaran Pendidikan Agama Islam. Bandung: Alfabeta.

Hamalik, Oemar. (2007). Proses Belajar Mengajar. Jakarta: Bumi Aksara.

Kholidah, Nurdiana. (2019). Implementasi Metode Ummi Dalam Meningkatkan Kemampuan Membaca Al-Qur'an Siswa Kelas III SDIT Insan Utama Bantul Yogyakarta. Skripsi. Universitas Islam Negeri Sunan Kalijaga. Yogyakarta.

Muthoifin \& Nuha. (2018). Mengungkap Isi Pendidikan Islam Perspektif Al-Qur'an Surat AlAshr Ayat 1-3. Surakarta: STIKES PKU Muhammadiyah Surakarta.

Usman, M. Uzer. (2010). Menjadi Guru Profesional. Bandung: PT. Remaja Rosda Karya. 